\title{
Anti-agalactosyl Immunoglobulin G Antibodies in Probable Rheumatoid Meningitis
}

Keiko Hatano ${ }^{1}$, Kazuto Katsuse ${ }^{1}$, Takeshi Suzuki ${ }^{2}$ and Hideji Hashida ${ }^{1}$

Key words: rheumatoid meningitis, rheumatoid factor, anti-cyclic citrullinated-peptide antibody, anti-agalactosyl immunoglobulin $\mathrm{G}$ antibody, antibody index

(Intern Med 59: 2637-2638, 2020)

(DOI: 10.2169/internalmedicine.5016-20)

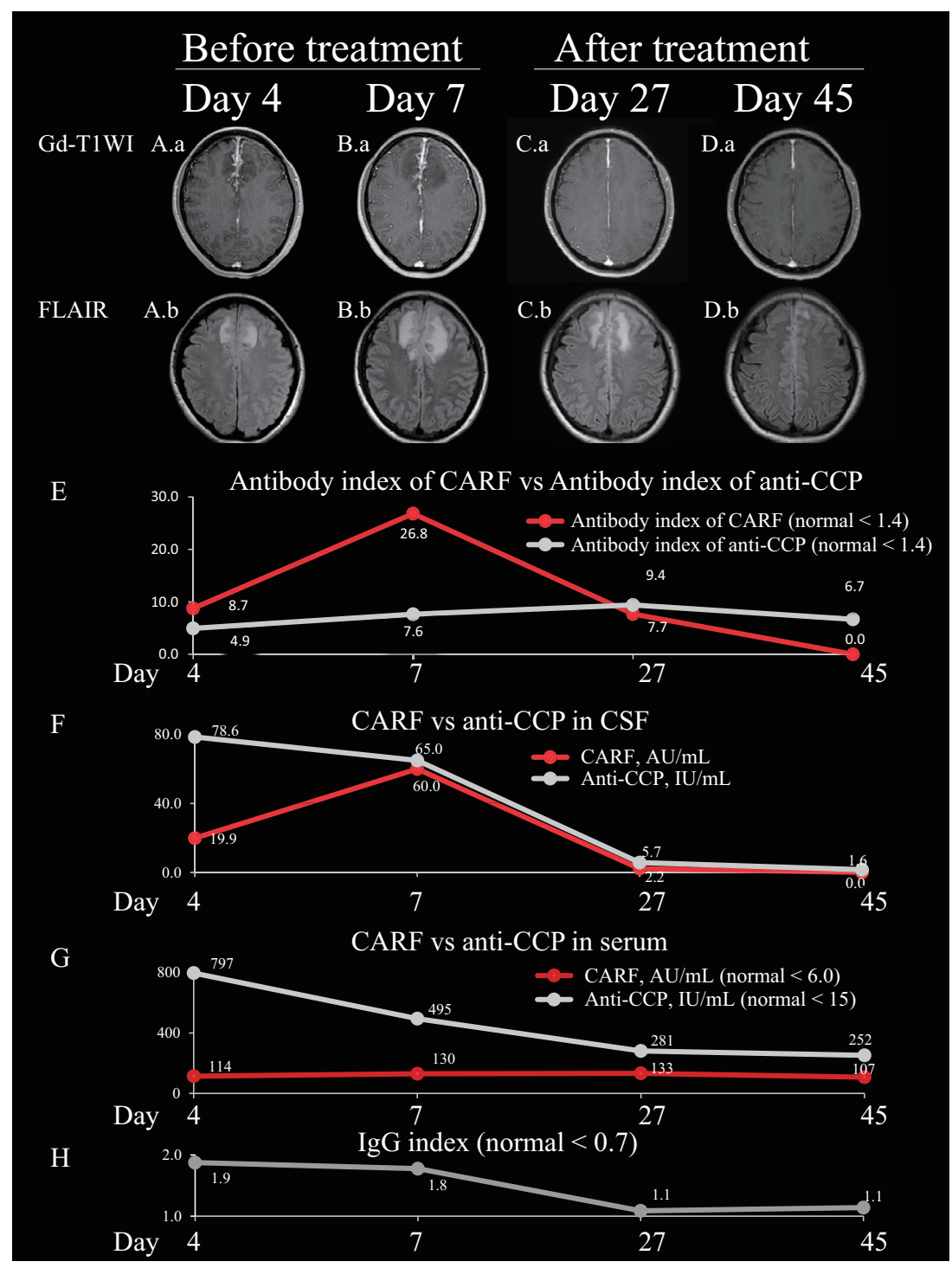

Picture.

${ }^{1}$ Department of Neurology, Japanese Red Cross Medical Center, Japan and ${ }^{2}$ Department of Allergology and Rheumatology, Japanese Red Cross Medical Center, Japan

Received: April 3, 2020; Accepted: May 18, 2020; Advance Publication by J-STAGE: July 7, 2020

Correspondence to Dr. Keiko Hatano, keikohatano@hotmail.co.jp 
A 53-year-old woman with rheumatoid arthritis (RA) in remission presented with headache, nausea, and non-fluent aphasia. After ruling out infection, tumors, and sarcoidosis, she was diagnosed with probable rheumatoid meningitis (RM) (1) based on elevated rheumatoid factor (RF), anticyclic citrullinated-peptide antibodies (anti-CCP), antiagalactosyl immunoglobulin $\mathrm{G}$ antibodies (CARF) in serum and cerebrospinal fluid (CSF), elevated antibody index (2) of anti-CCP and antibody index of CARF, magnetic resonance imagings (MRI) showing abnormal meningeal enhancement on gadolinium enhanced T1-weighted images (Gd-T1WI) and hyperintensity on fluid-attenuated inversion recovery (FLAIR) images (Picture A), and a positive response to steroids. Before starting treatment, her symptoms and MRI findings (Picture B) deteriorated, but after starting treatment with steroids on day 8 , they began to improve (Picture C, D) on day 13.

The antibody index of CARF and CARF in CSF reflected the disease activity with a higher sensitivity than the antibody index of anti-CCP, anti-CCP in CSF and serum, CARF in serum, and $\operatorname{IgG}$ index (Picture E-H), thus suggesting that
CARF in RM plays an intracranial pathophysiological role. To our knowledge, this is the first report to identify such a role for CARF in RM which also included the MRI findings. The activity of RA did not correlate with the activity of RM because the patient did not suffer a worsening of arthritis.

The authors state that they have no Conflict of Interest (COI).

\section{References}

1. Markenson JA, McDougal JS, Tsairis P, Lockshin MD, Christian CL. Rheumatoid meningitis: a localized immune process. Ann Intern Med 90: 786-789, 1979.

2. Reiber H, Peter JB. Cerebrospinal fluid analysis: disease-related data patterns and evaluation programs. J Neurol Sci 184: 101-122, 2001.

The Internal Medicine is an Open Access journal distributed under the Creative Commons Attribution-NonCommercial-NoDerivatives 4.0 International License. To view the details of this license, please visit (https://creativecommons.org/licenses/ by-nc-nd/4.0/).

(C) 2020 The Japanese Society of Internal Medicine Intern Med 59: 2637-2638, 2020 